\title{
Mental health: can we afford it?*
}

\author{
Geoffrey Wallis
}

"Man, through the use of his hands energised by will, can influence the state of his own health"

Anon, quoted at this conference by Christine Cratk

To find out if we can afford mental health we must discover its cost and proceedings at this conference, chaired by the presidents, Lord Ennals and Dr Fiona Caldicott, of the two colleges and attended by some 80 representatives of various disciplines, examined the cost of mental lliness in terms of money and also human suffering. Mr David Keay, secretary of 'Survivors Speak Out', thought that mental health services should to be so good that everybody suffering from mental illness would want them and there would be no crisis.

For community care, Dr Graham Thornicroft presented studies by himself and Dr Geraldine Strathdee on measurement of needs, demands, supply and cost effectiveness in a South London community. He foresaw dangers if funding were insufficient and the brokerage model inappropriate. Ms Judith Reid, Chief Occupational Therapist at the Maudsley Hospital, described the inability of people with acute mental illnesses to cope with daily living, the remedy being to reinstate them one step at a time into reality-based activities, a process which could take some time. Mrs Christine Craik, Chairman of the College of Occupational Therapists, said that occupational therapists, having always aimed to return patients to the community, were returning to their 1925 origins and had a major part to play in the target of The Health of the Nation to improve the health and social functioning of the mentally ill but were facing challenges in professionalism with its emphasis on degrees, research, body of knowledge, quality assurance and code of conduct; team concepts; and client-centred, needs-led orlentation in which consumer satisfaction surveys increased the empowerment of users and carers. Dr Jeannette Naish, who works academically and in practice in London, enquired whether general practitioners could

*Conference of the Royal College of Psychiatrists and the College of Occupational Therapists, 20 January 1994. influence purchasing decisions. She stressed that a mass of information about health needs held in general practices could be very helpful for purchasers but was not easily accessible. GP fund-holders were concerned with purchasing only some items of secondary care. In a study of adult psychiatric patients in the community in Hackney the proportion of unmet needs was high: $39 \%$ identified a need for activities but had to wait eight months for assessment by an occupational therapist. Professor Peter Tyrer, delineated an early intervention service centred on care worker in a team of 'commensables', this word deriving from communis, meaning 'joint' and 'community', mens, meaning 'mind' and habilis, meaning 'handy' and 'suitable'. By formal evaluation this model, compared with hierarchical and other ones, engaged more patients, who were more satisfied, and was cheaper. Mrs Jane Rennison, Head Occupational Therapist, supporting him, gave a neat example of assessment and energetic intervention in successful treatment in the community of a grossly deteriorated patient.

Sir Louis Blom-Cooper, as Vice-President of the College of Occupational Therapists, elegantly traced the course of legal developments. Many concerned bodies, including the Mental Health Act Commission in its fifth Biennial Report, wanted a review of the Mental Health Act which would provide for a comprehensive multidisciplinary approach to community care and introduce the principles of 'therapeutic jurisprudence' and reciprocity, whereby resources should match rights and compulsory measures. However, these measures would be expensive and the review would be difficult to arrange and take many years.

On more strictly economic topics, Ms Jennifer Beecham of the Personal Social Services Research Unit, University of Kent, related nonresource and resource inputs by way of costs to intermediate and final outcomes. The unit's researches indicated that not only was a homebased daily living programme cheaper and better than standard care but that for costeffectiveness private and voluntary services came first, social services second and the health authority third. The crunch came from Peter Gluckman and Paul Ward, Commissioners in 
the South-East London Health Authority, who estimated that the real cost to the nation of mental illness was $£ 22,066 \mathrm{~m}$ but official expenditure a mere $\$ 4266 \mathrm{~m}$. In light of this constraint they described their work as purchasers. They concluded that we could afford mental health only in areas of low prevalence of mental lliness and if healthy alliances replaced national and local barriers between government departments.

In discussion delegates emphasised the valuable contribution of occupational therapists to making a complete diagnosis. Dr Caldicott stressed that projects would fail if their duration of funding was less than six months at the very least. She said that the College had embarked on a nationwide project to gain information about the mentally ill and was reviewing the role of consultant psychiatrists in multidisciplinary teams.

The conference thanked Ms Judith Reid as the mainspring in organising this provocative, informative and synthesizing event.

Geoffrey Wallis, Consultant Psychiatrist, Harrogate Clinic, 23 Ripon Road, Harrogate HG1 2JL

\section{Meditation: bringing the mind home}

\section{Larry Culliford}

\section{Take a deep breath!}

This is a way of bringing the mind into the present moment. This simple exercise is a form of meditation.

The practice of meditation has a lot to do with keeping the mind both tranquil and alert; calm, aware, and focused within the present moment. It is a comfortable experience - that is why meditation is sometimes called. 'Bringing the mind home'.

There are various obstacles; and various techniques are taught to overcome these obstacles.

One of the obstacles involves confusing the practice of a technique with the practice of meditation. The difference is subtle, and in most cases the one leads to the other - but there is a difference.

Confidence and perseverance are necessary. It is often the case that one's practice is proceeding well, even (especially in the early stages) when it does not seem to be.

During the summer I was lucky enough to go on a canoe trip with friends in Canada. We covered about 100 miles in five days. This was on the Spanish River, a beautiful place.

For the final 20 miles or so the water ran swift and smooth. On our map this section was designated a 'Royal Ride' for canoeists, and so it proved. Effortlessly we doubled our previous average speed ... But to get that far we had endured four days of paddling: running aground. capsizing, repeatedly emptying the canoe of water, shooting the safer rapids and carrying canoes, tents, equipment and supplies around the more hazardous - including the awesome three-tiered so-called 'Graveyard' rapids, littered with the wreckage of many boats and canoes.

For many, meditation practice is like this difficult at the beginning.

I was new to canoeing, but those I was with were experienced. We had good canoes, good maps, enough food, proper tents and equipment. The weather was fair; and so with guidance I was quickly able to master the techniques and skills of canoeing.

So it was when I began meditation -12 or 13 years ago. But I have seen others give it a try and make only slow or limited progress - trying perhaps to set out upstream, as it were, against the obstacles of gravity and a fast current; perhaps expecting too much too soon.

This is why one is advised to find a good meditation teacher, someone with experience who will help one avoid mistakes and discouragement.

\section{About technique}

Meditation can be practised in any posture: sitting, kneeling, standing, walking or lying down. 